\title{
LOS GÉNEROS LITERARIOS EN EL PENSAMIENTO CRÍTICO DE WALTER BENJAMIN
}

Angélica Franken

\begin{abstract}
RESUMEN
En el contexto de su estudio de la modernidad y las relaciones entre arte y técnica, este análisis buscar dar cuenta del mapa que el crítico e intelectual Walter Benjamin delinea -no limita- en torno a los géneros literarios. Lo anterior a partir de su análisis de la figura de Baudelaire en el París del siglo XIX hasta llegar a Poe y la narrativa detectivesca, pasando a través de los géneros menores de las panorámicas y las fisiologías en un continuum histórico. Este recorrido narrativo convierte la materialidad de la modernidad en un problema literario y filosófico, y confirma que Benjamin escribe y lee por medio de su flâneur - héroe lo que se había volcado en palabras: la ciudad escrita de la modernidad.
\end{abstract}

Palabras claves: Modernidad, géneros literarios, ciudad, Baudelaire, Poe.

\section{THE LITERARY GENRES IN THE CRITICAL THINKING OF WALTER BENJAMIN}

\begin{abstract}
In the context of his study of modernity and the relationships between art and technique, this study aims to give an account of the map the critic and intellectual Walter Benjamin creates - not limits - around literary genres. The above starts with his analysis of the figure of Baudelaire in the XIX century Paris until reaching Poe and the detective narrative, passing through the minor genres of the panoramicas and physiologies in an historical continuum. This narrative journey converts the materiality of modernity into a literary and philosophical problem, and confirms that Benjamin writes and reads through his flâneur-hero what had turned into words: the written city of modernity.
\end{abstract}

Keywords: Modernity, literary genres, city, Baudelaire, Poe.

"La obra de Walter Benjamin no es homogénea ni en su organización temática ni en su facticidad $y$, menos aún, en su continua recepción hasta el día de hoy"

(Ralph Buchenhorst 11).

Angélica Franken - Candidata a Doctor en Literatura, mención chilena e hispanoamericana por la Universidad de Chile. Chilena, residente em Santiago - Chile. Email: angiefranken@gmail.com 


\section{Introducción: contexto de estudio}

La importancia que ha adquirido en los últimos años la figura intelectual de Walter Benjamin (1892-1940) ha sido abordada desde distintas disciplinas que, de una manera u otra, han intentado congeniar los variados frentes con que él ataca la cuestión de la modernidad, entre otros asuntos. Disciplinas como la filosofía, la historia, la antropología, los estudios culturales -medios de masas, estudios urbanos, etc.- y, por supuesto, la crítica literaria. Es factible acercarse individualmente desde cada uno de esos lentes críticos, no obstante, a mí parecer, es imposible comprender el Benjamin como crítico literario sin entender el Benjamin de las tesis sobre la historia o el de los pasajes. En este sentido, su alcance es más allá de lo literario y de la crítica literaria como tal. Quizás la imagen de un sistema abierto resulte clarificador, pero a la vez angustiante porque otro aspecto clave a la hora de comenzar a entender su pensamiento es asumir su fragmentariedad e inacabamiento.

A pesar de la aparente advertencia anterior, en este trabajo, se opta metodológicamente también por lo fragmentario - al igual que la materia de estudio - por una pequeña parte del sistema de relaciones benjaminianas. Se quiere pesquisar, en el contexto de estudio de la modernidad que realiza Benjamin, la configuración construida en torno a los géneros literarios a partir de su análisis de la figura de Baudelaire en el París del siglo XIX. A primera lectura, se vienen imágenes a la mente de folletines, de periódicos parisienses, del escritor Eugène Sue, de relatos de detectives, de Poe, de las fisiologías y del flâneur. Todos ellos, de un modo u otro, construyeron el imaginario literario del siglo XIX. Todos ellos participan de los procesos literarios de la modernidad, no obstante, no todos son abordados críticamente de la misma manera por Baudelaire en el siglo XIX y luego por Benjamin en el $X X$.

En ningún momento, se percibe en el intelectual alemán la intencionalidad de escribir una teoría de los géneros, intentos que sí tuvieron otros críticos literarios durante el siglo XX como Northrop Frye con su libro Anatomía de la crítica (1977) que construye un esquema complejo de la literatura entendiéndola como una estructura autónoma del lenguaje distinta de la crítica literaria la que trabaja allí 
donde las otras artes son mudas; o el análisis que realiza Mijail Bajtín en los años 30 caracterizado como "Poética histórica" que deconstruye la noción de contexto por la intertextualidad o interdiscursividad; o George Lukács en La teoría de la novela del año 1920 en la que los datos histórico-filosóficos se imponen a la creación en la diferencia entre épica y novela. ${ }^{1}$ Todos estudios que buscan conformar, de manera más o menos consciente, un sistema que tiene como núcleo clave el género de la novela vinculado a la modernidad.

Naturalmente, en la idea de una conformación de una teoría de los géneros benjaminiana entran factores como las transformaciones de los medios mismos de comunicación con el surgimiento del periodismo capitalista que altera las nociones de narrador, lector, y de la comunicación misma; en otras palabras, un acercamiento y una escuela sociocultural de los géneros. Por lo mismo, este análisis busca más bien el modo en que Benjamin arma y caracteriza los géneros modernos que recorren su análisis de Baudelaire en París o el París de Baudelaire. Estudiar los géneros que delinea -no limita- en un continuum histórico. Esto último no en el sentido de que sigue una línea cronológica del surgimiento de éstos -los orígenes son desconocidos y no se entra en detalles de una genealogía-, pero sí un género abordado va desencadenando en el otro el que a su vez contiene restos o huellas de todos los anteriores. Por ejemplo, el relato de detectives contiene algunos elementos del folletín y del género de las fisiologías, los versos de Baudelaire también dan cuenta a nivel de forma y contenido las transformaciones de la modernidad. Por ningún motivo, se pretende insinuar una teoría cerrada o acabada de los géneros -es un cauteloso acercamiento- si la característica principal del trabajo crítico de Benjamin es su inacabamiento y fragmentariedad ${ }^{2}$. Este análisis no se aleja del método de su objeto de estudio: el arte de citar, la fragmentariedad y la no cerradura.

Por lo mismo, el objetivo es centrarse principalmente en los textos de Benjamin en torno a la modernidad y a la figura de Baudelaire, el último gran poeta masivo, en su texto El París del Segundo Imperio en Baudelaire (1938) que luego es

\footnotetext{
${ }^{1}$ Estos son algunos autores entre muchos que han intentado dar respuesta al concepto de literatura y de género. Se mencionan en este análisis sólo en función de contraparte a la postura de Benjamin. Se menciona esto puesto que este trabajo no busca comparar las diferentes teorías que se han dedicado al asunto del género.

2 Cfr. SARLO, Siete ensayos sobre Walter Benjamin (2000).
} 
reelaborado en Sobre algunos temas en Baudelaire (1939). La figura de poeta francés transita los géneros que revisita Benjamin por lo que siempre late la pregunta del vínculo de la poesía de Baudelaire con estos otros géneros vinculados al periodismo como el folletín y, posteriormente, los relatos de detectives. Para Benjamin, estos géneros son los propios del París de la modernidad y su vínculo con el género de la novela es más indirecto. El análisis no se centra en las características del género lírico o de la poesía del poeta, sino más bien de la influencia de estos otros géneros de la modernidad que influyeron, de modo directo, la poesía de Baudelaire y lo convirtieron en el último gran lírico de las multitudes. Una aproximación a los géneros que destaca Benjamin debe ser a través de los géneros que Baudelaire manejó y criticó. Es decir, hay que pasar por Baudelaire para llegar a ellos, él es el medio, como para llegar a Poe también hay que pasar por Baudelaire.

Ahora bien, cabe señalar que la misma figura de Baudelaire tampoco es acabada y contiene una serie de incongruencias que marcan este acercamiento a los géneros: "Hacia 1850, Baudelaire proclama que el arte es inseparable de la utilidad; pocos años más tarde defenderá el "I'art pour l'art". Esta cita es significativa porque precisamente una de las grandes interrogantes de este estudio es cuán crítica es la mirada de Benjamin hacia los géneros que se analizan aquí en el sentido de si pertenecen o no a un arte con potencialidad revolucionaria y que permite la experiencia en la ciudad; pregunta que probablemente no sea respondida, más que superficialmente, en estas líneas. Sin embargo, según el propio Benjamin, esta aparente contradicción no es tal y más bien refleja la superioridad de Baudelaire sobre los asuntos y la actividad literaria que lo rodeaba ${ }^{4}$. Aparente superioridad o excentricidad que también dibujaba la imagen del intelectual alemán Walter Benjamin.

Por último, la escritura genérica que buscan estas líneas no se pueden separar del contexto de producción y de la técnica que marcó el siglo XIX. En esta línea, Benjamin pertenecería al grupo de críticos que defiende una sociología de la cultura y el arte- perspectiva de análisis bastante recurrente y central de toda la crítica académica de la obra benjaminiana. De hecho, un texto que podría ser clave

\footnotetext{
3 BENJAMIN, El París de Baudelaire, p. 69.

${ }^{4}$ Cfr. BENJAMIN, El París de Baudelaire, p. 86.
}

Angélica Franken - Candidata a Doctor en Literatura, mención chilena e hispanoamericana por la Universidad de Chile. Chilena, residente em Santiago - Chile. Email: angiefranken@gmail.com 
para iniciar una teoría de los géneros como es El narrador -en torno a la narración y el narrador- está más preocupado de los alcances éticos que estéticos de la figura ${ }^{5}$. Por lo mismo, se desconoce en la academia un acercamiento centrado exclusivamente en el mapeo genérico, en la ciudad de los géneros por donde transitan los personajes y héroes de Baudelaire, de Poe y el hombre de la multitud. Por este camino, quiere serpentear este análisis.

\section{Modernidad: arte y técnica}

"Esta nueva forma de la comunicación es la información"6.

Algo seguro para este acercamiento a la obra benjaminiana es que su potencial teoría de los géneros está en el meollo mismo de las transformaciones de la técnica y el arte. Posiblemente, el texto de Benjamin que da mejor cuenta de esto es "La obra de arte en la era de la reproductibilidad técnica" (1936). El primer gran cambio en la literatura fue la reproductibilidad que permitió la imprenta y que acompaña al género de la novela. Ahora bien, este ensayo de Benjamin problematiza otro aspecto de la reproductibilidad, la pérdida del aquí y ahora de la obra de arte que representaba su autenticidad ${ }^{7}$; pérdida del aura que coloca a ésta en una aparición masiva en vez de su aparición única ${ }^{8}$. Ejes de este cambio de paradigma son la fotografía y el cine. Transformaciones de los medios que alteran también los fines que persiguen el arte y la figura del espectador o, para este análisis, del lector en el contexto de los movimientos de masas.

Esta alteración del valor cultual o ritual del arte por la repetitividad de la reproducción, también se desplaza a la dimensión narrativa. Aquí es clave el texto El narrador (1936) que profundiza la diferencia entre narración y novela, teniendo la primera el carácter ritual y de la experiencia que valora Benjamin y que lamenta su pérdida con el periodismo vinculado a la mercancía. El eje de todo el relato es la pérdida de la experiencia "por obra del despliegue de la tecnología en la modernidad" " "El fin del arte de narrar, que supone la clausura de un modo atávico

\footnotetext{
${ }^{5}$ Cfr. OYARZÚN en BENJAMIN, EI narrador, p. 8.

BENJAMIN, El narrador, p. 67.

Cfr. BENJAMIN, Estética y política, p.87.

Cfr. Ibidem, p.89.

9 OYARZÚN en BENJAMIN, El narrador, p. 8.
}

Angélica Franken - Candidata a Doctor en Literatura, mención chilena e hispanoamericana por la Universidad de Chile. Chilena, residente em Santiago - Chile. Email: angiefranken@gmail.com 
de transmisión de la experiencia basado en la producción artesanal, clausura que coincide con la emergencia de la novela"10. La oposición más ejemplar de su argumentación es narración y novela como artesanía y técnica ${ }^{11}$. La vinculación de la novela con la técnica es en relación a que ésta no está destinada a ser compartida en comunidad, sino a ser leída a través del soporte del libro destinado al consumo individual $^{12}$.

Como bien señala Oyarzún en su prólogo a la traducción de El Narrador, este desarraigo que Benjamin teoriza en el género de la novela llega a su clímax con la prensa puesto que "lleva la mediación tecnológica a un ápice en el cual se cumple la serialidad y la universalidad indiferente que albergaba la invención de la imprenta"13. En cierto sentido, pareciera que Benjamin estaba desconociendo o ignorando conscientemente las potencialidades de la experiencia que la novela también puede desarrollar precisamente en relación a las transformaciones de la forma ${ }^{14}$. Lo significativo, para este análisis, es el acercamiento que Benjamin tiene hacia la prensa -"tiempo de la información es el presente perentorio y fugaz del interés en la noticia, presente que conocemos bajo el nombre de actualidad"15 - que se rige por el instante y la nueva información. Lo nuevo y su proyección en la mercancía es el régimen de la modernidad.

Por todo lo mencionado, el surgimiento de las masas y sus nuevos modelos de comunicación necesitaron una refuncionalización de los géneros clásicos entiéndase lírica, drama, épica- en sintonía también con la perspectiva del público y la modificación de los modelos de distribución, eje central del ensayo "El autor como productor" (1934). Se podría leer incluso que la pérdida de la experiencia ha favorecido el intertexto genérico por sobre el ritual y las experiencias sociales, es decir, la comunidad se reúne ahora en el espacio e imaginario del género ${ }^{16}$. Eso sí, nuevos géneros asociados ahora a la mercancía: "El arte que empieza a dudar de su tarea y deja de ser "inseparable de l'utilité" [Baudelaire] debe hacer de lo nuevo su

\footnotetext{
${ }^{10}$ Ibidem, p. 16.

${ }^{11}$ Cfr. OYARZÚN en BENJAMIN, El narrador, p. 21.

${ }^{12}$ Cfr. Ibidem, p. 22

${ }_{13}^{13}$ Ibidem, p. 23.

${ }^{14}$ Resulta interesante tal vez para otro trabajo analizar el acercamiento de Benjamin a novelistas como Proust y Kafka y de qué modo éstos se vinculan con la modernidad y deslindan los límites del género.

${ }^{15}$ OYARZÚN en BENJAMIN, El narrador, p.25.

${ }^{16}$ Cfr. ALTMANN, Los géneros cinematográficos, p.254.
}

Angélica Franken - Candidata a Doctor en Literatura, mención chilena e hispanoamericana por la Universidad de Chile. Chilena, residente em Santiago - Chile. Email: angiefranken@ gmail.com 
valor principal"17. El siglo XIX será el de las novedades y el espacio de éstas será París, capital del siglo XIX.

\section{Transformaciones: la prensa y el folletín}

"Con el folletín del diario, las belles lettres consiguieron una salida de ventas en el periódico"18.

Si se entra en el imaginario de la prensa y la literatura, las primeras imágenes que se vienen a la mente son los nombres de Alexandre Dumas, Víctor Hugo, George Sand, Eugéne Sue, Honore Balzac, entre otros, escritores de novelas que se vincularon e influenciaron, de modo más o menos consciente y libre, por el nuevo sistema, y fueron publicados dentro del formato de novelas por entregas que son a fin de cuentas las precursoras del folletín ${ }^{19}$. El periódico fue el soporte que, por una parte, les permitió llegar a un número más grande de lectores y, por otra, vivir holgadamente de su oficio. A fin de cuentas, surgen nuevas relaciones económicas y políticas de este soporte y de las aventuras que ofrece a sus seguidores. Innumerables son las citas fragmentarias de Benjamin ante todo en el Libro de los pasajes (1927-1940, obra inacabada) donde cita la invitación a Dumas a colonizar Argelia, la candidatura a diputado de Eugène Sue o el aumento de separaciones matrimoniales que provocaron las novelas de Sand. Como se puede ver, las repercusiones van mucho más allá del universo literario.

En el primer apartado del ensayo El París del Segundo Imperio en Baudelaire (1938) titulado "La Bohème", Benjamin recorre las llamadas "mercancías literarias cotidianas" y deambula en torno a la nueva figura del escritor, a los lectores masivos, a los temas literarios y al proceso de producción vinculado al café y al boulevard. Estas transformaciones confirman que en "ningún otro ámbito fueron más claros los efectos distorsionadores del capitalismo como en el de la producción literaria” ${ }^{20}$. En efecto, el momento del aperitivo surge con la prensa sensacionalista y el material de rumor y cotilleo ${ }^{21}$. "La asimilación del literato a la sociedad en que se hallaba ocurría

\footnotetext{
${ }^{17}$ BENJAMIN, El París de Baudelaire, p.58.

${ }^{18}$ BENJAMIN, El París de Baudelaire, p.86.

${ }^{19}$ Cfr. BENJAMIN, Libro de los pasajes, p. 774.

${ }^{20}$ BUCK-MORSS, Walter Benjamin y el proyecto de los pasajes, p. 156.

${ }^{21}$ Cfr. BENJAMIN, El París de Baudelaire, p. 88.
} 
en el boulevard de la siguiente forma. Allí, el literato se mantenía abierto a algún incidente provechoso, broma o rumor"22. Hay un nuevo espacio, el boulevard y el café; un nuevo tiempo de sociabilidad, el aperitivo; una nueva disposición, alerta y curiosa; un nuevo material, accidentes, rumores, cotilleo, entre otros. El literato, entendido como el que se dedica a las letras, se comporta "como si hubiera aprendido de Marx que el valor de cada mercancía está determinado por el tiempo de trabajo socialmente necesario para su producción" ${ }^{23}$. La ociosidad -tiempo muerto creativo- traía su recompensa.

Así como el folletín -"sección especial de los periódicos masivos para literatura y reseñas, donde las novelas aparecían en episodios antes de su publicación como libros" ${ }^{24}$ - es el desencadenante lógico de las novelas por entregas, éstas son el de los anuncios, modo de subsistencia de los periódicos y causa de la disminución de abonos que obliga a que "la cuarta página, que se había convertido en una afiche, debía pasar ante los ojos de la mayor cantidad posible de abonados" 25 . Los anuncios permitieron el autofinanciamiento de los periódicos, la potencialidad del formato de novelas por entregas, y las grandes sumas de dinero para aquéllos que se unieran al desafío. El privilegio del dinero pasó al ámbito de la fama y lo político, y confirmó el vínculo entre el hecho político y la acción literaria ${ }^{26}$ : Dumas fue convidado a colonizar Argelia, Sue es elegido diputado, se escriben los folletines de jornadas políticas de Balzac, Sue insulta a la religión para "servir a las enemistades del Constitutionnel"27, entre otros. Benjamin dedica varias líneas a la corrupción que circundó al ahora mercado literario y recurre a Baudelaire ${ }^{28}$ y su imagen de la prostituta para graficarlo. Claramente, Benjamin escoge a Baudelaire como objeto de estudio precisamente porque era el primer ejemplo de narrador independiente al mercado literario ${ }^{29}$, pero no ajeno a sus influencias.

En el apartado "La Bohème", Benjamin no realiza una crítica explícitamente literaria al contenido o calidad estética de las novelas de entregas o los folletines,

\footnotetext{
${ }^{22}$ Ibidem, p. 88.

${ }^{23}$ BENJAMIN, El París de Baudelaire, p. 89.

${ }^{24}$ BUCK-MORSS, Walter Benjamin y el proyecto de los pasajes, p. 60.

${ }^{25}$ BENJAMIN, El París de Baudelaire, p.89.

${ }^{26}$ Cfr. BUCK-MORSS, Walter Benjamin y el proyecto de los pasajes, p. 161.

${ }^{27}$ BENJAMIN, El libro de los pasajes, p. 761.

${ }^{28}$ En la Bohème, Benjamin da cuenta de cómo Baudelaire representa en sus poemas los problemas de los que habla Marx y el tema de la revolución (cf. BENJAMIN, EI Paris de Baudelaire, p. 80).

${ }^{29}$ Cfr. BUCK-MORSS, Walter Benjamin y el proyecto de los pasajes, p. 159.
} 
sino más a bien a cómo dan cuenta de las transformaciones de la técnica en el proceso literario: "la moda de publicación en folletines, que obligaba, a cada nuevo capítulo, a sorprender con un gran golpe de efecto al lector, había impulsado los efectos y los tonos de la novela a un diapasón extremo, desesperante" 30 . El género de la novela es alterado. El soporte ya no es el mismo -paso de la unidad libro al fragmentario periódico-, la forma es transformada en función de la recepción del lector -golpes de efecto- y los temas son de gusto popular -el cotilleo urbano. Los redactores no daban pie ni exigían que los folletinistas escribieran sobre una creencia o una verdad ${ }^{31}$.

A fin de cuentas, los escritores de novelas por entregas y folletines plasmaron en sus escritos el cambio de soporte y de imaginario. El objetivo está centrado en el uso, en la recepción, en el interés de las clases más numerosas de la sociedad. Lo significativo es que el desarrollo de estos formatos dio pie a otros géneros y estilos narrativos y conforman un imaginario genérico vinculado directamente a los procesos socioculturales. Su material y formato es la modernidad. Por lo recién dicho, es clave el estudio de estos géneros periodísticos o propios del formato del periódico. Sin embargo, su valor democrático, la disminución de la distancia entre autor y lector -asunto trabajado ante todo en el ensayo "El autor como productor"-, mientras estuviera bajo los parámetros de la mercancía, se manifiesta como manipulación y promueve un consumo pasivo antes que una activa colaboración ${ }^{32}$. Por lo mismo, el "el potencial democrático de las masas permanecía irrealizado"33.

\section{Literatura panorámica, género de la fisiología}

"Si quisiéramos hablar de un artilugio de las fisiologías, será entonces el acreditado por el folletín: convertir el boulevard en interior"34.

Si en el apartado anterior se afirmó que el escritor entra al mercado a escuchar o robar confesiones, Baudelaire agrega que éste entra como un flâneur a

\footnotetext{
${ }^{30}$ BENJAMIN, El libro de los pasajes, p. 767.

${ }^{31}$ Cfr. Ibidem, p. 778.

${ }^{32}$ Cfr. BUCK-MORSS, Walter Benjamin y el proyecto de los pasajes, p. 159.

${ }^{33}$ Ibidem.

${ }^{34}$ BENJAMIN, El París de Baudelaire, p.100.
} 
contemplar el mercado y buscar un comprador ${ }^{35}$. El mercado se vuelve para él panorama, y combina el capital con el paisaje. Benjamin introduce un género literario particular bajo el rótulo de literatura panorámica ${ }^{36}$. La anécdota propia de los libros construía el primer plano de estos panoramas y con la descripción y la información el fondo o la profundidad de campo de las mismas. Benjamin utiliza una nomenclatura propia de las artes plásticas para definir el género: figuras, bosquejos, primer plano, plano de fondo, etc. Entonces, la literatura panorámica podría ser una pintura escrita o escritura pictórica. A fin de cuentas, la literatura con su palabra novelesca ajena construía panoramas donde los nuevos protagonistas de la modernidad deambulaban. Al igual que los folletines, muchos autores se dedicaron a este género destinado a un público masivo y destinado "al desgaste de la calle"37.

La literatura panorámica buscaba reproducir "una imitación perfecta de la naturaleza a través de los medios técnicos"38. En este sentido es que los panoramas dan cuenta de un cambio en las relaciones entre arte y técnica ${ }^{39}$. Ahora, es posible llevar el paisaje consigo en el anhelo del hombre de ciudad de transportar el campo a su nuevo hogar: "en los panoramas la ciudad se abre transformándose en paisaje" ${ }^{40}$; paisaje por donde el flâneur transita. Si la ciudad se vuelve la profundidad de campo de esta literatura panorámica, también sucede que ciertos personajes de la modernidad se constituyen adornos: [...] "aquí aparece por última vez el trabajador fuera de su clase, como ornamento de un idilio" ${ }^{41}$. Ya en estas líneas se insinúa una cierta ingenuidad previa del género que Benjamin critica y seguirá haciéndolo después con el género de las fisiologías.

La literatura panorámica que pasa a ser un tipo de escritura incluía otro formato, los physiologies, que correspondían a descripciones de tipos que transitan y se vinculan al espacio del mercado ${ }^{42}$. "Desde los vendedores ambulantes del boulevard hasta los elegantes en la recepción de la ópera: no había figura de la vida

\footnotetext{
${ }^{35}$ Cfr. Ibidem, p. 96.

${ }^{36}$ Cfr. Ibidem, p. 97.

37 BENJAMIN, El París de Baudelaire, p. 97.

38 lbidem, p. 49.

${ }^{39} \mathrm{Cfr}$. Ibidem.

40 lbidem, p. 50.

41 Ibidem, p. 49.

${ }^{42}$ Cfr. Ibidem, p. 97.
}

Angélica Franken - Candidata a Doctor en Literatura, mención chilena e hispanoamericana por la Universidad de Chile. Chilena, residente em Santiago - Chile. Email: angiefranken@gmail.com 
parisina que el physiologue no hubiera retratado" ${ }^{\text {"3 }}$. Las fisiologías eran el alimento diario y tuvieron su apogeo en los años 40 del siglo XIX, tras los cuales vino la decadencia. No obstante, fueron la antesala de los folletines y de las novelas por entregas. Cabe destacar dos aspectos de análisis crítico en este género categorizado como pequeño-burgués: primero, la ironía de Benjamin cuando señala que Baudelaire tuvo que sufrirlas y que no le prestó mucha atención; segundo, que la aparente razón de su paulatina fuera de escena es que abarcó profundidades de campo más complejas: pasó del retrato a la fisiología de la ciudad y de los pueblos, y luego incluso de los animales.

Por lo mencionado, pareciera que Baudelaire no le dio gran importancia, sin embargo, su desarrollo es clave para el surgimiento de la novela de detectives y sus retratos de la ciudad y el crimen. Entonces, a la vez que podemos vincular la literatura panorámica con un lenguaje pictórico, y a las fisiologías con la necesidad de dotar de información al primer plano y al de fondo de los mismos panoramas, se pueden distinguir dos niveles en la conformación de estos géneros pequeñoburgueses: una razón técnica y una razón social -Benjamin los relaciona a la fotografía, pero son aplicables a la literatura. La razón técnica, la construcción de los panoramas en sus diferentes planos que incluyen la profundidad de campo de la ciudad y del mercado y el adorno superficial -primer plano- de los personajes que transitan la urbe y el boulevard; y la razón social, el anhelo del hombre de ciudad de llevarse el campo a la ciudad y poblar el mercado.

No cabe duda que Benjamin es escéptico frente a estos géneros. En un principio, la crítica pareciera ser su ausencia de ideología, su ingenuidad o, incluso, su superficialidad -sobreabundancia de adornos- luego, se comprueba lo contrario. De hecho, el surgimiento de las fisiologías tiene que ver con la censura de las "Leyes de septiembre" de 1936 producto de las cuales ciertos sátiros debieron alejarse de la política y optar por un género ingenuo ${ }^{44}$ : "Lo apacible de estas descripciones se armoniza con la actitud del flâneur, que va tomando muestras botánicas por el asfalto" ${ }^{\text {. }}$. La supuesta inocencia del género no fue tal porque "si quisiéramos hablar de un artilugio de las fisiologías, será entonces el acreditado por el folletín: convertir

\footnotetext{
${ }^{43}$ Ibidem, p. 98.

${ }^{44}$ BENJAMIN, El París de Baudelaire, p. 98.

${ }^{45}$ lbidem, p. 99.
}

Angélica Franken - Candidata a Doctor en Literatura, mención chilena e hispanoamericana por la Universidad de Chile. Chilena, residente em Santiago - Chile. Email: angiefranken@gmail.com 
el boulevard en interior" ${ }^{\prime 4}$. Entonces, al convertir el boulevard en interior, en la casa del flâneur, la calle en apartamento, éste mismo ejerce el trabajo de fisiologista y coopera con la fantasmagoría parisina.

Quizá la crítica vaya por el lado de que las fisiologías, por ser un género propiamente burgués, favoreció el proceso de la mercancía: “El pensamiento político oculto en ese género de escritos al que pertenecen las fisiologías era entonces: la vida, en toda su multiplicidad, en su inagotable riqueza, prospera solo entre los empedrados grises y ante el fondo gris del despotismo" ${ }^{47}$. Éste distanciamiento crítico sería en relación a la sumisión a la mercancía, pero las fisiologías eran una escritura sospechosa también en lo social: "Las largas series de caracteres, estrafalarios o simples, ganadores o severos, presentadas al lector por las fisiologías, tenían algo en común: eran inocentes, de una bonhomía perfecta" ${ }^{48}$, es decir, de una afabilidad, sencillez y bondad que paradójicamente no era inocente. Por el contrario, tenía precisamente la función de opacar el extrañamiento en las nuevas relaciones en la gran ciudad y el nuevo e inevitable contacto físico y, sobre todo, visual mayor producto de los desplazamientos a través de la urbe gracias al transporte público.

En relación a lo anterior, para "las fisiologías era conveniente dejar de lado, por insignificantes, estas o similares representaciones que inspiraban inquietud. Las fisiologías representaban, si es posible decirlo así, las anteojeras del "obtuso hombre moderno" del que habla Marx en algún momento" ${ }^{49}$. Es decir, contribuían al mecanismo de la apariencia que ya circundaba la mercancía y que se amplía a la sociedad total. "Ciertamente, lo primero era ofrecer a la gente una imagen agradable de unos y otros. De esta forma las fisiologías también tejían, a su modo, parte de la fantasmagoría de la vida parisina" ${ }^{\text {50 }}$. He en estas líneas el principal cojeo de este género. Su fin u objetivo no es inocente e ingenuo, sino calculado para mantener un status quo. Finalmente, aportan a la construcción de la fantasmagoría de la ciudad cuyo núcleo es la mercancía. Su estudio crítico es, entonces, clave para entender las nuevas dinámicas de la modernidad.

\footnotetext{
${ }^{46}$ Ibidem, p. 100.

47 BENJAMIN, El París de Baudelaire, p. 100.

48 Ibidem.

49 Ibidem, p. 101.

50 Ibidem, p. 102.
}

Angélica Franken - Candidata a Doctor en Literatura, mención chilena e hispanoamericana por la Universidad de Chile. Chilena, residente em Santiago - Chile. Email: angiefranken@gmail.com 
Luego, las fisiologías toman un vuelco que las relaciona con otro género clave para Baudelaire y Benjamin: las historias de detectives. Esto último en base a la capacidad de los fisiologistas de reconocer tipos en medio de la multitud. Si la ciudad crecía y con ella la fauna de citadinos, si la ciudad crecía y se volvía un lugar menos agradable, era clave tener personas con olfato para distinguir. El resultado es establecer más clases y divisiones entre los ciudadanos, y recrear un ambiente tranquilo. No obstante, los fisiologistas no duraron mucho tiempo, puesto que la literatura en su afán intranquilizador y amenazante de la vida en la ciudad, dejó de lado las fisiologías y se dedicó a investigar la función de las masas dentro de la ciudad. Poe abusa de las fisiologías y las transforma precisamente para mostrar el lado más oscuro de la masa. En este sentido, la fisiología da pie al surgimiento del asocial dentro de la ciudad, personaje clave de los nuevos relatos detectivescos y que fue, además, un objeto lírico para Baudelaire.

Lo anterior es clave en el acercamiento a Baudelaire y marca una diferencia para el Benjamin crítico entre las fisiologías, la poesía y la literatura de detectives. Si las primeras pudieron retratar -con lo que el término literalmente significa- a la ciudad como panorama, los otros géneros previos -en este caso la lírica- sufrieron esas transformaciones en su estructura interna. "Dupont sintió llegar la crisis de la poesía lírica con la disgregación progresiva entre ciudad y campo [...]", ahora "el poeta presta sus oídos a veces al bosque; otras a las masas"”51. Por lo mismo, el eje de la obra de Baudelaire y de la mirada del alemán sobre éste está en los cambios de temas: la mercancía, y de escenario y fondo de escritura/producción: la ciudad. "Con Baudelaire París se convierte por primera vez en el objeto de la poesía lírica" 52 . También en el género lírico, el objeto lírico es la modernidad y la actitud lírica son los nuevos movimientos y esquemas que la rigen.

Sin lugar a dudas, tanto Baudelaire como, posteriormente, eran conocedores del género de las fisiologías y modificaron sus cimientos. De hecho, Benjamin actualiza la figura de Baudelaire haciendo también una fisonomía de su figura, y el poeta francés lo hace con Poe. Todo lo anterior renueva la idea de que el problema de Benjamin no es con la técnica y las repercusiones de la modernidad, sino con el uso político incorrecto de éstas. De cierto, su escepticismo frente al folletín y el

\footnotetext{
${ }^{51}$ BENJAMIN, El París de Baudelaire, p. 84.

52 Ibidem, p. 56.
}

Angélica Franken - Candidata a Doctor en Literatura, mención chilena e hispanoamericana por la Universidad de Chile. Chilena, residente em Santiago - Chile. Email: angiefranken@gmail.com 
género de las fisiologías anticipa o presagia sus trabajos sobre la estetización de la vida política, que llevó al fascismo en el siglo XX, y su intento de hacer, más bien, una politización del arte con fines revolucionarios. Esto último en relación a que estos géneros que son reflejos a nivel de materia y forma de los avances tecnológicos no significaron un movimiento ilustrado paralelo, y desembocaron en el nacionalsocialismo, que es finalmente la unión del irracionalismo político con la idea de crear una técnica que mostrara a un pueblo en vías de conquista. 


\section{Poe y los relatos de detectives}

"[...] composiciones extrañas, que parecen haber sido creadas para demostrarnos que lo extraño es una de las partes integrantes de lo bello",53.

Si bien Benjamin dedica varias líneas al género de la literatura panorámica y de las fisiologías en relación a que estos grafican literariamente las transformaciones y dilemas de la modernidad, para el Benjamin crítico literario no se sitúan en el mismo nivel artístico que la poesía de Baudelaire y las historias de detectives de Poe. Para este análisis, lo interesante de esta variedad genérica es el continuum, el paso ahora de estos formatos vinculados a la fotografía y a la técnica hacia los relatos de detectives. La literatura de los panoramas -la ciudad convertida en paisaje- se conecta con Poe y su obra porque el personaje protagonista y el fondo es el mismo: el flâneur-detective que transita por el boulevard y entre la multitud que esconde/revela al asocial. Por lo señalado, en este apartado, se quiere indagar a su vez en la valoración que hace el también crítico literario Baudelaire de la obra literaria de Edgar Allan Poe (1809-1849) y de la cual se vale, posteriormente, Benjamin para acercarse a los dos poetas.

Al igual que la literatura de fisiologías, estos relatos se preocupan del nuevo escenario, pero desde una perspectiva diferente: "Aquí la masa aparece como el asilo que protege al asocial de sus perseguidores" ${ }^{54}$. La flânerie ofrece, en términos de Benjamin, la mejor perspectiva de este efecto peligroso de las multitudes, porque el flâneur juega al incógnito, al desconocido, y se configura al ritmo de la ciudad y sus recovecos ${ }^{55}$. De esta manera, se construye un imaginario en torno al flâneur, detective o asocial, que sirve paralelamente de material para publicaciones de folletines o novelas por entregas como Los Mohicanos de París de Alexandre Dumas, escrita entre 1854 y 1855 en la cual "el héroe decide salir a la aventura siguiendo un pedazo de papel que ha soltado a los juegos del viento" ${ }^{56}$. El detective citadino de Dumas busca una señal que lo lleve tras una pista y una historia que lo conduzca por la ciudad. Esta referencia al maestro de las novelas por entregas

\footnotetext{
${ }^{53}$ BAUDELAIRE, Edgar Allan Poe, p. 54.

${ }^{54}$ BENJAMIN, El París de Baudelaire, p. 104.

${ }^{55}$ Cfr. Ibidem, p. 104-5.

${ }^{56}$ Ibidem, p. 105.
}

Angélica Franken - Candidata a Doctor en Literatura, mención chilena e hispanoamericana por la Universidad de Chile. Chilena, residente em Santiago - Chile. Email: angiefranken@gmail.com 
aparecida también en el Libro de los pasajes (1927-1940) refiere a una suerte de imaginario común entre los escritores vinculados al periódico del cual se vale Benjamin para su análisis.

En la producción literaria, el surgimiento masivo de las historias de detectives se concretiza con los cuentos de Poe traducidos al francés por Baudelaire, quien consideraba a Poe el mejor representante de la nueva literatura. ¿Cuáles eran las características de esta nueva literatura? El crítico alemán destaca la apropiación de otros géneros y registros: "experimentó con el relato científico, con la cosmogonía moderna, con la representación de figuras patológicas" ${ }^{27}$. Es decir, el hecho de que vincule literatura y ciencia, literatura y filosofía. Este último aspecto es clave del análisis literario que hace el mismo Baudelaire de Poe cuando lo define como "poeta, novelista y filósofo". En Poe, confluyen tres aspectos primordiales para el poeta de Las flores del mal (1857): "Para resumir, diré que los tres caracteres de los novelistas curiosos son: 1. un método privado; 2. lo sorprendente; 3. la manía filosófica, tres caracteres que constituyen en definitiva su superioridad"58. De hecho, una separación de las disciplinas artísticas y científicas sería leída como un suicido artístico para Baudelaire y para Benjamin que busca la conciliación entre la filosofía y el problema de la crítica literaria ${ }^{59}$.

En relación a un método particular, Benjamin incluso señala que Poe es uno de los mayores "técnicos" de la nueva literatura. No es azaroso que utilice el término "técnica" para caracterizar un autor fruto de la modernidad. Pareciera que este adjetivo se vincula con la apropiación de un modelo único y propio y de un método que ambiciona universalidad ${ }^{60}$ y que necesita del vínculo e influencia con otras ciencias. El valor que Benjamin otorga, luego, a Poe es que al igual que Baudelaire tiene un método personal y éstos se asemejan. Incluso, afirma que analizar la obra de Poe es disecar la de Baudelaire aunque éste no haya escrito nunca relatos de detectives. Baudelaire es el Poe de Francia y Poe es el Baudelaire de Londres y Estados Unidos. Los dos son poetas lo cual confirma cierta disposición hacia el género por el intelectual alemán. Ahora bien, más allá de entrar en similitudes autobiográficas, la vida del escritor maldito -exactamente su vínculo a la embriaguez

\footnotetext{
${ }^{57}$ BENJAMIN, El París de Baudelaire, p. 107.

${ }^{58}$ BAUDELAIRE, Edgar Allan Poe, p. 16.

${ }^{59}$ Cfr. BENJAMIN, El París de Baudelaire, p. 107.

${ }^{60}$ Cfr. Ibidem.
}

Angélica Franken - Candidata a Doctor en Literatura, mención chilena e hispanoamericana por la Universidad de Chile. Chilena, residente em Santiago - Chile. Email: angiefranken@ gmail.com 
como estado alucinatorio- comparten la "manía filosófica", la búsqueda de un método singular y la inclinación por personajes y escenarios propios de la modernidad. De hecho, el poemario Las flores del mal (1857) incluye en sus versos los elementos de un relato de detectives de Poe: una víctima, un lugar del crimen, un asesino y las masas $^{61}$. Según el crítico alemán, el único motivo de que Baudelaire no escribiera relatos de detectives es que no era capaz de identificarse con el héroe detective, puesto que lo hacía con el asocial. Baudelaire no escribió relatos de enigma, no utilizó el formato, pero sí sus componentes.

Benjamin establece, en el análisis de la obra de Poe, un nexo entre el problema de fondo del cuento "El misterio de Marie Rogêt" (1843) -la historia de la joven desaparecida y asesinada cuyo enigma descifra el detective Auguste Dupin a través del análisis de los periódicos parisinos que escribieron sobre el controvertido caso- y el soneto "A une passante" en Las flores del mal de Baudelaire. A simple vista de un lector, son dos construcciones literarias diferentes. $Y$ lo son, pero Benjamin ahonda en la transformación que se revela del imaginario de la multitud. Si en el caso de Marie Rogêt, la suposición señalaba que era imposible que ella no fuese vista por algún conocido en las calles aledañas a su casa, es decir, que no fuera reconocida por y en la masa de personas que transita periódicamente por su barrio; en el caso del soneto "A une passante", el asunto de la masa refiere precisamente a lo contrario, a que la mujer paseante/transeúnte se pierde en medio de la masa después de un segundo de reconocimiento por un otro ya enamorado que se lamenta: “¡En todo caso lejos, ya tarde, tal vez nunca!/Que no sé a dónde huiste, ni sospechas mi ruta,/ ¡Tú a quien hubiese amado. Oh tú, que lo supiste!" 62. En este poema, la multitud ya no es el asilo del criminal -como en el caso del cuento "El hombre de la multitud" (1840)-, sino "el asilo del amor que escapa al poeta"63. La multitud ya no en su influencia en la existencia ciudadana, sino en la del poeta erótico al cual la multitud le entrega la experiencia del amor.

El poeta experimenta en el espacio de la masa el schock, noción vinculada directamente a la experiencia de la modernidad y que puede ser un factor en esta revisión genérica para distinguir una literatura de otra observando con los ojos de

\footnotetext{
${ }^{61}$ BENJAMIN, El París de Baudelaire, p. 98.

${ }^{62}$ Cfr. BAUDELAIRE, "A une passante", ciudadseva.

${ }^{63}$ BENJAMIN, El París de Baudelaire, p. 110.
} 
Benjamin. De hecho, el ensayo revisado de El París del Segundo Imperio en Baudelaire (1938) titulado Sobre algunos temas en Baudelaire (1939) tiene como eje de análisis la experiencia del schock a nivel individual y cómo el poeta es capaz tanto de producirlo como de experimentarlo. ${ }^{64}$ Los versos de Baudelaire traslucen el choque "con que el solitario se ve atravesado cuando, sin mediación alguna, lo invade un capricho imperioso" ${ }^{65}$ : el capricho del amor y el deseo. Finalmente, las nociones de análisis que entran en juego y permiten una comparación literaria entre este poema de Baudelaire y el cuento de detectives de Poe son la multitud y el shock/encuentro que ésta posibilita.

Siguiendo el vínculo anterior con la masa y la experiencia en ella, es interesante el cuento "El hombre de la multitud" (1840) que es "algo así como la radiografía de una historia de detectives" ${ }^{66}$. En esa historia de Poe, están los componentes claves de todo relato de detectives y una suerte de esquema base de este tipo genérico. Inclusive hay una reflexión sobre el fenómeno mismo que permite el surgimiento del género: la curiosidad que convierte a un simple ciudadano en un perseguidor; un crimen, en este caso desconocido, que exige la búsqueda de una verdad; un escenario que favorece y permite el acto criminal y una intriga o secreto que es el motor del relato ${ }^{67}$. Para Baudelaire, el desconocido es un flâneur, pero según Benjamin, para Poe, este flâneur no está vinculado a la confabulación que caracteriza la perspectiva de Baudelaire, puesto que para Poe es "alguien que no está seguro en su propia sociedad"68. De ahí la imagen del desconocido dando vueltas toda la noche por el mismo centro. Ni siquiera en miedo de la multitud se siente seguro. En este sentido, "Poe borronea la diferencia entre el asocial y el flâneur" ${ }^{69}$ y éste se hace más sospechoso mientras más se oculta en medio de la multitud.

\footnotetext{
${ }^{64}$ Por un tema de extensión, en este análisis no se incluirá una revisión exhaustiva de la noción de shock. Sí se aludirá a ella en relación a una experiencia que caracteriza al poeta y que éste debe crear en la modernidad que padece precisamente la ausencia de ésta o su acostumbramiento.

65 BENJAMIN, El París de Baudelaire, p. 111.

${ }^{66}$ Ibidem, p. 114.

${ }^{67}$ Cfr. FRANKEN, Crimen y verdad en la novela policial chilena actual (2003).

68 BENJAMIN, El París de Baudelaire, p. 114.

69 Ibidem.
} 
En "El hombre de la multitud", el narrador que observa la multitud en su calidad de vitrina ${ }^{70}$ lo hace desde un café: "Sentía un interés sereno, pero inquisitivo, hacia todo lo que me rodeaba. Con un cigarro en los labios y un periódico en las rodillas, me había entretenido gran parte de la tarde, ya leyendo los anuncios, ya contemplando la variada concurrencia del salón, cuando no mirando hacia la calle a través de los cristales velados por el humo"71. La alegre disposición, el espíritu curioso -aspecto que Baudelaire destaca de la figura de Poe y que lo identifica con este narrador- permite ahora la experiencia de choque o encuentro: "Pegada la frente a los cristales, ocupábame en observar la multitud, cuando de pronto se me hizo visible un rostro (el de un anciano decrépito de unos sesenta y cinco o setenta años) que detuvo y absorbió al punto toda mi atención, a causa de la absoluta singularidad de su expresión. Jamás había visto nada que se pareciese

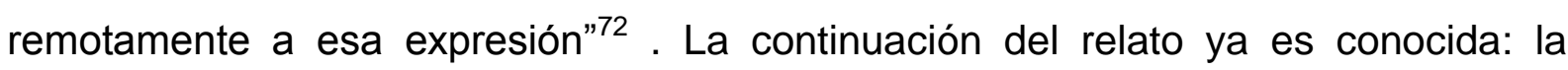
persecución por el siempre centro de la ciudad y la autoafirmación: "Este viejo -dije por fin- representa el arquetipo y el genio del profundo crimen. Se niega a estar solo. Es el hombre de la multitud"73. A fin de cuentas, este relato ahonda en dos variantes del imaginario del flâneur: por un lado, es el narrador en su calidad de ocioso dispuesto a seguir una pista; por otro, la del perseguido asocial que huye por las calles del centro de Londres.

Lo expresado en el párrafo anterior se vincula con otro aspecto crítico que Benjamin aborda en su objetivo de vincular el registro filosófico - literario con la materialidad de la modernidad. Tiene que ver con los juegos de luz y noche que marcan el ritmo temporal del mismo relato. El desconocido criminal huye mientras se oscurece y van comenzando a prenderse los faroles a gas: "[...] los resplandores del gas, débiles al comienzo de la lucha contra el día, ganaban por fin ascendiente y esparcían en derredor una luz agitada y deslumbrante. Todo era negro y, sin embargo, espléndido, como el ébano con el cual fue comparado el estilo de Tertuliano"74. La novela de detectives no es la misma sin los faroles a gas que "aumentaban la seguridad en la ciudad; y hacían que la multitud, en la calle,

\footnotetext{
${ }_{71}^{70}$ Cfr. SILVA, Imaginarios urbanos, p. 124.

${ }_{72}^{71}$ POE, "El hombre de la multitud", ciudadseva.

72 Ibidem.

${ }^{73}$ Ibidem.

${ }^{74}$ Ibidem.
}

Angélica Franken - Candidata a Doctor en Literatura, mención chilena e hispanoamericana por la Universidad de Chile. Chilena, residente em Santiago - Chile. Email: angiefranken@ gmail.com 
estuviera como en casa también por la noche"75. Entonces, la noche y el noctambulismo aparecen como los nuevos protagonistas y escenarios temporales de los cuentos literarios, y en su materialidad en los faroles de gas se basa Poe para articular el tiempo del relato de la modernidad. La ciudad, la multitud y los contactos citadinos se articulan temporalmente en función de la nueva luz.

También gracias a esa luz, Poe recurre al género de la fisiología -género menor que seguro era de su conocimiento- para describir a los pequeños burgueses que se mueven entre la multitud durante el atardecer estableciendo tipos humanos que, aparentemente, no se alejan de la bohomía que caracterizaba a esos textos: "La división formada por los empleados superiores de las firmas sólidas, los «viejos tranquilos», era inconfundible. Se los reconocía por sus chaquetas y pantalones negros o castaños, cortados con vistas a la comodidad" ${ }^{\prime 76}$. El narrador de Poe describe a estos sujetos clasificándolos a la vez en clases sociales -la masa diferenciada-, desde los empleados públicos a las prostitutas: "el vejestorio lleno de arrugas, joyas y cosméticos, que hace un último esfuerzo para salvar la juventud; la niña de formas apenas núbiles, pero a quien una larga costumbre inclina a las horribles coqueterías de su profesión, mientras arde en el devorador deseo de igualarse con sus mayores en el vicio" 77 . Sin embargo, a diferencia del género de las fisiologías que buscaba figurar tipos humanos agradables dentro de la ciudad para evitar conmociones citadinas, Poe destaca el carácter demoníaco de estas figuras y su carácter inhumano: "Me acuerdo de que, al contemplarla, mi primer pensamiento fue que, si Retzch la hubiera visto, la hubiera preferido a sus propias encarnaciones pictóricas del demonio" ${ }^{\prime 78}$.

Por lo anterior, Poe deconstruye el género de las fisiologías -que estaba en su apogeo precisamente en los años 40-para convertir a la multitud no sólo en el asilo del asocial, sino también del abandonado y embriagado por la mercancía ${ }^{79}$. Los citadinos descritos son aquéllos que, al igual que el perseguidor que mira sin ser observado desde el café, transitan las grandes avenidas y boulevards cautivados e hipnotizados por ella, moviéndose al ritmo y tropiezo de la misma: "Entró de tienda

\footnotetext{
${ }^{75}$ BENJAMIN, El París de Baudelaire, p. 117.

${ }^{76}$ POE, "El hombre de la multitud", ciudadseva.

77 Ibidem.

${ }^{78}$ Ibidem.

${ }^{79}$ Cfr. BENJAMIN, El París de Baudelaire, p. 123.
}

Angélica Franken - Candidata a Doctor en Literatura, mención chilena e hispanoamericana por la Universidad de Chile. Chilena, residente em Santiago - Chile. Email: angiefranken@ gmail.com 
en tienda, sin informarse de nada, sin decir palabra y mirando las mercancías con ojos ausentes y extraviados" ${ }^{\prime 80}$. El desconocido intenta ocultarse y lo hace reproduciendo las acciones cotidianas de la multitud. Por lo mismo, en Poe encontramos una de las mejores fisonomías de la multitud "que es el velo a través del cual la ciudad habitada se le aparece al flâneur como fantasmagoría" ${ }^{\text {. }}$.

Finalmente, este cuento es la radiografía de los relatos de detectives, la obra base que prefigura las transformaciones del género en la novela de detectives y luego en la novela policial y negra ${ }^{82}$. Poe transforma el artefacto al publicar estos relatos en el periódico, al desestabilizar el género de las fisiologías reproduciendo personajes extraños e inhumanos, al caracterizar de otro modo la multitud. A su vez, da cuenta del objetivo central de la crítica literaria de Baudelaire y, luego, Benjamin: convertir la materialidad de la modernidad en un problema literario y filosófico. Por todo lo anterior es que es un escritor fundamental del análisis literario tanto de Baudelaire como de Benjamin. En este punto, es clave recordar el libro de Baudelaire titulado Edgar Allan Poe, que recopila diez breves ensayos o columnas de periódico escritos entre los años 1848 y 1864, y que delinea la figura compleja de Poe como poeta y filósofo. Después de su lectura, es posible ver en la crítica literaria de Benjamin otros niveles de significación que están asumidos en su acercamiento a Baudelaire.

\section{Conclusiones: crítica literaria y contenido de verdad}

"No tiene a la verdad por objeto, sólo se tiene a sí misma",83.

"[...] ¿por qué no confesar que lo que ha sostenido mi voluntad ha sido el placer de presentarles un hombre que en algunos aspectos se me parecía un poco, o sea una parte de mí mismo" "84. Estas líneas del poeta francés de Las flores del mal confirman un presentimiento que recorre todas las páginas de este trabajo: una

\footnotetext{
${ }^{80}$ POE, "El hombre de la multitud", ciudadseva.

${ }^{81}$ BENJAMIN, El París de Baudelaire, p. 57.

${ }^{82}$ Para ver la influencia de Poe en la narrativa detectivesca y, posteriormente, en sus variantes policial y negra, léase el libro Crimen y verdad en la novela policial chilena actual (2003) de Clemens Franken.

83 BAUDELAIRE, Edgar Allan Poe, p. 105.

84 Ibidem, p. 124.
}

Angélica Franken - Candidata a Doctor en Literatura, mención chilena e hispanoamericana por la Universidad de Chile. Chilena, residente em Santiago - Chile. Email: angiefranken@gmail.com 
posible identificación entre Baudelaire y Poe. Los dos son poetas, los dos surgen en la modernidad, los dos conocen las nuevas reglas del campo literario -periodismo- y, finalmente, los dos vinculan a un método literario particular la reflexión sobre el proceso mismo puesto que hace de la materialidad de la modernidad una reflexión literaria y filosófica. Podríamos agregar a este paralelo o semejanzas que construyen una imagen crítica ${ }^{85}$, un tercer integrante, Walter Benjamin, que precisamente toma como objeto de estudio al poeta francés $y$, sin poder evitarlo, también al poeta estadounidense. Es como se dijo en páginas anteriores, para leer a Baudelaire hay que pasar por Benjamin, y para leer a Poe hay que pasar por Baudelaire. El sistema de identificaciones es tal que una lectura fragmentaria nos llevaría de fragmento en fragmento sin acabar.

El crítico alemán establece múltiples puntos de fuga entre ambos poetas y críticos literarios, y afirma que Baudelaire no escribió relatos de detectives porque el héroe flâneur de Baudelaire se vinculaba más con el asocial que con el héroe detective de Poe. En su análisis formal, no sólo destaca al Poe poeta, sino también al novelista que escribe relatos en los que "la unidad de impresión, la totalidad de ese efecto es una ventaja inmensa que puede dar a ese género de composición una superioridad realmente particular, hasta el punto que un relato demasiado corto -lo que es sin duda un defecto- es preferible a un relato excesivamente largo" ${ }^{\text {" }}$. El valor agregado del relato, en este caso detectivesco, es la intensidad del efecto de unidad de impresión que la poesía, al parecer, no tendría tan marcadamente. Siguiendo a Baudelaire, las diferencias entre estos relatos novelescos y otros géneros no están en su unidad de composición, sino de efecto. La brevedad, pero a la vez unidad de impresión del relato breve, ofrece mayores libertades ${ }^{87}$. En relación a lo anterior, Baudelaire establece otra diferencia entre la lírica y la narrativa que sería la mayor apertura de temas que ofrece ésta última; temas "más variados y más fácilmente apreciables por el común de los lectores" ${ }^{\prime 8}$. En todas las apreciaciones señaladas entran en función aspectos no de la estructura interna de la obra, sino de su recepción (el lector) y modo de producción, lo que Bajtín denominaba lo extraliterario.

\footnotetext{
${ }^{85}$ SARLO, Siete ensayos sobre Walter Benjamin, p. 51.

${ }^{86}$ BAUDELAIRE, Edgar Allan Poe, p. 98.

${ }^{87}$ Cfr. Ibidem, p. 99

${ }^{88}$ Ibidem.
}

Angélica Franken - Candidata a Doctor en Literatura, mención chilena e hispanoamericana por la Universidad de Chile. Chilena, residente em Santiago - Chile. Email: angiefranken@ gmail.com 
Tras lo mencionado, reaparece una interrogante latente de este análisis. Por qué motivo Benjamin no realiza un análisis más exhaustivo de la novela en el siglo XIX, sino que se queda estacionado en la poesía de Baudelaire que se articula en torno a otros géneros menores vinculados al periodismo como fueron los folletines, la literatura panorámica y las fisiologías. Se acerca efectivamente a la narrativa por medio de estos últimos y del análisis de los relatos detectivescos de Poe, pero no entra de lleno en el género propio de la modernidad: la novela decimonónica. La respuesta a esto es insuficiente y especulativa. Sí se acercó a la novela en autores posteriores como Marcel Proust $^{89}$ (1871-1922) y Franz Kafka (1883-1924) que escenificaron el cambio de siglo y las nuevas técnicas literarias. En todo caso, la respuesta parece estar en que sí elaboró una teoría del género de la novela, y lo hizo no explícitamente por medio de la configuración de su héroe: el flâneur. Si se revisan los ejemplos que se dieron en la introducción de críticos literarios como Frye, Bajtín o Lukács, se comprueba que el núcleo de sus sistemas literarios es el héroe. Por ejemplo, Frye (1977) construye su teoría de los modos en torno al héroe y su poder de acción sobre o bajo la naturaleza dentro del mundo relato; Lukács (1920) y Bajtín (1930) lo articulan como un ente en proceso de formación.

Siguiendo el argumento señalado, Benjamin también comparte la percepción de la novela como género inacabado y en proceso de formación, y no hay más claro ejemplo que el recorrido genérico que se ha hecho en estas páginas. En el caso de Benjamin, las transformaciones del formato novelesco se articulan en relación al contexto sociocultural de la modernidad. Su perspectiva va más allá del plano discursivo. Se puede afirmar que el arte no es lo mismo que cultura, no obstante, para Benjamin, los dos actúan por osmosis. Escribe y lee por medio de su flâneur héroe lo que se había volcado en palabras: la ciudad escrita de la modernidad. Por lo mismo, su análisis crítico-literario debía pasar de la ciudad de París a la ciudad escrita por el flâneur; por ello, su crítica literaria es a la vez crítica de la cultura. A fin de cuentas, aborda la literatura y su campo de experiencia desde afuera, desde la materialidad de la modernidad que la literatura, y en especial la novela, plasma a nivel de forma y contenido. Incluso, tanto Poe en un nivel como Baudelaire en otro

\footnotetext{
${ }^{89}$ El acercamiento de Benjamin a Proust se arma en torno al asunto de la memoria que en este escritor se articula como memoria automática o involuntaria en su obra En busca del tiempo perdido (1913-1927). Esto es analizado por Benjamin en algunos aparados en Sobre algunos temas en Baudelaire (1939), y sigue trabajando con ello en el ensayo "A una imagen de Proust" (1929).
}

Angélica Franken - Candidata a Doctor en Literatura, mención chilena e hispanoamericana por la Universidad de Chile. Chilena, residente em Santiago - Chile. Email: angiefranken@gmail.com 
dan figura a su imagen de artistas siguiendo la del héroe flâneur ${ }^{90}$ : la literatura y la realidad también confluyen. En resumen, con el acercamiento crítico a géneros menores y, luego, a los poetas del flâneur, Benjamin configura lo que sería su teoría de la novela.

Tras lo señalado, reaparece otra pregunta que subyace a este análisis y que Benjamin responde desde otros asuntos críticos: dónde radica la gran diferencia entre los llamados géneros pequeño-burgueses y la escritura de Poe. Se afirmó que este último reapropia el género de las fisiologías y describe a la multitud en su lado inhumano. La multitud, que fue el gran motivo literario de los escritores del siglo XIX, adquiere en la obra de Baudelaire y Poe un carácter distinto. Por ejemplo, en "A une passante", deja de ser hostil y es precisamente el lugar que permite "un amor no sólo a primera vista sino también a última" ${ }^{91}$ que es posible de experimentar únicamente en una gran ciudad; en "El hombre de la multitud", es la gente de Londres -fisonomía de los tipos de la masa- la que revela un aire inquietante. Para Baudelaire, el que recorre ambas muchedumbres es el flâneur; para Benjamin, el perseguido maníaco de Poe dista mucho del flâneur baudelaireano donde la actitud de relajación es la que prevalece ${ }^{92}$.

El flâneur que recorre ambos imaginarios de la multitud no es el mismo, pero comparte una característica que hace que la obra de Poe y Baudelaire tenga el valor que le asigna Benjamin: incluye la experiencia del choque. Los formatos vinculados a la información periodística -novedad, brevedad, claridad y fragmentariedad- dan cuenta de las transformaciones del medio, de la técnica en la modernidad, y son formas potencialmente democráticas, accesibles a la masa y que disminuyen la barrera entre el productor literario y la audiencia ${ }^{93}$; no obstante, no traspasan la barrera del valor ilustrativo de estos mismos cambios o, en algunos casos, no pasan más allá de ser meras ilustraciones de temas revolucionarios. "La forma estratégica más importante del escritor no es tanto rellenar de contenido revolucionario las

\footnotetext{
${ }^{90}$ Cfr. BAUDELAIRE, Edgar Allan Poe, p. 140.

${ }^{91}$ BENJAMIN, El París de Baudelaire, p. 204.

${ }^{92}$ Cfr. lbidem, p. 209.

${ }^{93}$ Cfr. BUCK-MORSS, Walter Benjamin y el proyecto de los pasajes, p. 156.
} 
nuevas formas literarias, sino desarrollar el potencial revolucionario ${ }^{94}$ de las formas mismas" $"$.

En el corpus de textos y géneros que ha recorrido este análisis, el potencial revolucionario se encuentra en los poemas de Baudelaire y en los cuentos de Poe en permitir la experiencia por sobre la vivencia. Por lo mismo, para hablar de los géneros de la experiencia fue necesario pasar por los de la vivencia: las fisiologías, la literatura panorámica, el folletín. En este punto, vuelve a resaltar la figura del poeta y su vínculo indisoluble con el novelista. El poeta, como héroe de la modernidad, es el que posee una conciencia muy alta -que es diferente a la conciencia falsa que no deja aparecer la experiencia verdadera- la que organiza poéticamente los choques. Es decir, el poeta Baudelaire y el poeta Poe harían visibles y efectivos los choques que ya no se percibía en la vida moderna. Entonces, éstos -por manos del poeta- se vuelven creativos y se convierten en material poético. En este sentido, el trabajo poético no es ingenuo, sino una razón de estado que se emancipa de la vivencia y permite la epifanía -experiencia verdadera- que la modernidad habría arrebatado a los habitantes de la ciudad, tal como se representa en el cuento "El hombre de la multitud" de Poe. Finalmente, la figura del narrador que es desarrollada a cabalidad en el texto El Narrador- no es la única o central, sino que el eje que posibilita la experiencia verdadera en la modernidad es el poeta, cuyo máximo representante es Baudelaire. He aquí que el corpus narrativo de Benjamin se construya en torno a su creación literaria y figura.

Por lo tanto, la producción de sentido crítico ha de estar involucrada en la misma praxis literaria. Con esta afirmación, se vuelve a retomar el concepto de crítica de arte de Benjamin, la criticabilidad interna de la obra y el contenido de verdad que es presentado como problema filosófico ${ }^{96}$. En concreto, si Baudelaire y Poe compartían la búsqueda de lo bello en la lírica -anhelo que ya no existía en los nuevos medios técnicos-, esta búsqueda no es de tipo moral o pedagógica, pero sí una reflexión del asunto de la verdad, como problema filosófico. En Poe, el crimen

\footnotetext{
${ }^{94}$ Benjamin va a graficar esto en la figura de Bertolt Brecht en el ensayo "El autor como productor" (1934) para distinguir el escritor operante del que sólo informa o es un rutinero. En ese texto, también ahonda en las características de un arte verdaderamente revolucionario que no es el objeto de estudio de este análisis.

95 Ibidem, p. 157.

${ }^{96}$ BENJAMIN, Obras. "El concepto de crítica de arte en el Romanticismo alemán”, p. 184.
} 
no es abordado como hecho o asunto psíquico o social, sino como una reflexión sobre el método de descubrimiento: la verdad no es descubierta luego de que sucedió un hecho, sino es creada antes que aparece como descubierta. La detección no se origina en la lógica del personaje, sino en la del autor ${ }^{97}$. Entonces, la crítica se encuentra contenida en la obra misma, y la forma como tal se convierte en una reflexión sobre el arte como medio de verdad. El contenido de verdad en la obra de Baudelaire y Poe está ya inmerso en su propia praxis como escritores -de ahí, la importancia de sus figuras-, pero no es extraíble deductivamente más que en su ejercicio particular de la literatura.

Finalmente, ante la afirmación de que el discurso literario no es discurso filosófico, se plantea el problema de la crítica como un problema filosófico. De hecho, quizás con Benjamin o sólo con él, el discurso filosófico se ha hecho cargo del discurso literario. En su estudio de la protohistoria de la modernidad, delinea con trazos finos, abiertos y fragmentarios -como las citas del Libro de los Pasajes- un mapa genérico de la capital moderna, el París del siglo XIX, la ciudad de los géneros. En ésta, destaca Baudelaire, el último gran poeta de las multitudes, cuyo libro, Las flores del mal, se convirtió en un clásico y presentó reediciones como ningún otro. La razón de su popularidad radica quizás en que como ningún otro poeta futuro supo revelar las apariencias y desapariencias de la modernidad. Benjamin afirma que es el poeta de la experiencia.

${ }^{97}$ Cfr. FRANKEN, Crimen y verdad en la novela policial chilena actual (2003).

Angélica Franken - Candidata a Doctor en Literatura, mención chilena e hispanoamericana por la Universidad de Chile. Chilena, residente em Santiago - Chile. Email: angiefranken@gmail.com 


\section{REFERENCIAS}

ALTMAN, Rick. Los géneros cinematográficos. Barcelona: Paidós, 2000.

BAJTíN, Mijaíl. Problemas estéticos y literarios. Editorial Arte y Literatura, 1986.

BAUDELAIRE, Charles. Edgar Allan Poe. Trad. Carmen Santos. Madrid: La Balsa de la Medusa, 1988.

.A

une

passante"

http://www.ciudadseva.com/textos/poesia/fran/baudelaire/transeunte.htm.

BENJAMIN, Walter. EI París de Baudelaire. "París, capital del siglo XIX", "EI París del Segundo Imperio en Baudelaire", "Sobre algunos temas en Baudelaire". Trad. Mariana Dimópulos. Buenos Aires: Eterna Cadencia Editora, 2012.

Estética y política. "La obra de arte en la era de la reproductibilidad técnica". Trad. Tomás Joaquín Bartolletti y Julián Fava. Buenos Aires: Las cuarenta, 2009.

Metales Pesados, 2010.

El Narrador. Trad. y notas Pablo Oyarzún. Santiago: Ediciones

Libro de los pasajes. Ed. Rolf Tiedemann. Madrid: Akal, 2005.

"El concepto de crítica de arte en el Romanticismo alemán".

Ed. Rolf Tiedemann. Madrid: Abada Editores, 2007.

BUCK-MORSS, Susan. Dialéctica de la mirada. Walter Benjamin y el proyecto de Ios Pasajes. Trad. Nora Rabotnikof. Madrid: La Balsa de la Medusa, 2001.

FRANKEN, Clemens. Crimen y verdad en la novela policial chilena actual. Santiago: Ediciones Universidad de Santiago, 2003.

FRYE, Northrop. Anatomía de la Crítica. Caracas: Monte Avila Editores, 1991.

LUKÁCS, George. Teoría de la novela. Buenos Aires: Ediciones Siglo Veinte, 1966.

POE, Edgar Allan Poe. "El hombre de la multitud" (1940)

http://www.ciudadseva.com/textos/cuentos/ing/poe/hombre.htm

"El misterio de Marie Roget" (1943)

http://www.ciudadseva.com/textos/cuentos/ing/poe/misterio.htm

SARLO, Beatriz. Siete ensayos sobre Walter Benjamin. Buenos Aires: Fondo de Cultura Económica, 2000.

SILVA, Armando. Imaginarios urbanos: Bogotá y Sao Paulo. Bogotá: Tercer Mundo Editores, 2000. 
Angélica Franken - Candidata a Doctor en Literatura, mención chilena e hispanoamericana por la Universidad de Chile. Chilena, residente em Santiago - Chile. Email: angiefranken@gmail.com 